\title{
Evaluation questionnaire for PERA
}

\author{
Task Force
}

13.1 ARCHITECTURE ${ }^{1}$ (All answers in italics)

\subsubsection{Users of the architecture}

What is the intended/targeted audience of this architecture?

No answer provided

\subsubsection{Intended scope of architecture}

Please check those activities which are in the intended scope of the architecture (in the short term, i.e. $2-3$ years)

\begin{tabular}{|c|c|c|c|}
\hline $\begin{array}{c}{[]} \\
\text { covered } \\
\text { context }\end{array}$ & $\begin{array}{c}\text { partially cov- } \\
\text { ered context }\end{array}$ & $\begin{array}{c}{[]} \\
\text { context not } \\
\text { covered }\end{array}$ & $\begin{array}{c}{[]} \\
\text { no } \\
\text { information }\end{array}$ \\
\hline
\end{tabular}

Example

[ ] [ ] [ ] [ ] product research and development

[ ] [ ] [ ] [ ] customer services, product maintenance

[ ] [ ] [ ] [ ] product management, marketing function, strategic

[ ] [x] [ ] [ ] product distribution

[ ] [ ] [ ] [ ] marketing

[ ] [x] [ ] [ ] product design

$[\mathrm{f}][\mathrm{x}][\mathrm{]}$ production planning

[ ] [x][ ][ ] manufacturing control

[ ] [x] [ ] [ ] manufacturing

[ ] [x] [ ] [ ] material handling, storage and transport

1. Questionnaire filled in by Peter Bernus after the Melbourne Task Force Meeting, May 1992; answers are based on T. J. Williams' answers to Questionnaire Version 2 and on discussions at the Melbourne Task Force Meeting. 
$[\mathrm{c}][\mathrm{x}][\mathrm{]}] \mathrm{]}$ testing and quality control

[ ] [x] [ ] [ ] logistics

[ ] [x] [ ] [ ] acquisition

[ ] [ ] [ ] [ ] legal services

[ ] [ ] [ ] [ ] personnel services finance, accounting

[ ] [ ] [ ] [ ] infrastructure, archiving and library services

[ ] [x] [ ] [ ] infrastructure, communications (excluding computer communications)

[ ] [x] [ ] [ ] information technology infrastructure, including computer communications, computing, database management, etc.

[ ] [x] [ ] [ ] education

[ ] [x] [ ] [ ] strategic enterprise management

[ ] [ ] [ ] [ ] market research

[ ] [ ] [ ] [ ] resource management

[ ] [ ] [ ] [ ] factory development /development of the production facility)

[ ] [ ] [ ] [ ] project management

[ ] [ ] [ ] [ ] factory design

[ ] [ ] [ ] [ ] factory building and modernization

[ ] [ ] [ ] [ ] factory maintenance

[ ] [ ] [ ] [ ] infrastructure, energy

[ ] [ ] [ ] [ ] infrastructure, buildings and grounds

[ ] [ ] [ ] [ ] other (please specify)

Note: where there is no ' $x$ ', answer was not provided

\subsubsection{What is the highest intended level of genericity on which this architecture is applicable? (check one)}

[x] every type of enterprise

[ ] certain type of industry (please specify which one)?

What is the area of industry in which the architecture has already been applied? The architecture is too new for it to have been applied yet

13.1.4 Which stage of systems development is addressed by the architecture? (multiple choice question)

\begin{tabular}{|c|c|c|c|}
\hline $\begin{array}{c}{[] \text { fully }} \\
\text { covered }\end{array}$ & $\begin{array}{c}\text { [] partially } \\
\text { covered }\end{array}$ & {[] not covered } & $\begin{array}{c}{[] \text { no }} \\
\text { information }\end{array}$ \\
\hline
\end{tabular}

Example

[x] [ ] [ ] [ ] requirements

[x] [ ] [ ] [ ] implementation (configuration and reconfiguration) 

$[\mathrm{x}][\mathrm{]}] \mathrm{]}][\mathrm{]}$
$[\mathrm{x}][\mathrm{]}] \mathrm{]}[\mathrm{]}$ operation and maintenance

\subsubsection{What are the goals which we would like to attain by developing generic CIM architectures? (Which are the main factors of industry's need?)}

(Please concentrate on the user requirements of a prospective utilizing industry.)

\begin{tabular}{|c|c|c|c|}
\hline $\begin{array}{c}\text { [] essential } \\
\text { factor }\end{array}$ & $\begin{array}{c}{[] \text { important }} \\
\text { factor }\end{array}$ & $\begin{array}{c}{[] \text { advantageous }} \\
\text { but not essential }\end{array}$ & $\begin{array}{c}{[] \text { not }} \\
\text { important }\end{array}$ \\
\hline
\end{tabular}

[x] [ ] [ ] [ ] better use of current resources

[x] [ ] [ ] [ ] integration of current technology

[ ] [ ] [ ] [ ] cutting excessive costs of having to develop CIM systems individually

[x] [ ] [ ] [ ] improve the quality of the developed individual systems/ manufacturing systems/CIM systems,etc.

[ ] [ ] [x] [ ] enabling the development of a marketplace for compatible CIM products

[ ] [ ] [ ] [ ] obtain flexibility in system and adaptation to change in requirements

\subsubsection{De facto scope and detail}

This question is about how completely the architecture has been defined relative to its intended scope (see Question 2) and its intended detail.

No sufficient information available at this stage

\subsubsection{Omissions}

(a) Please check and give details if needed):

[x] the architecture covers its promised intended scope

[ ] the architecture omits some necessary detail (please specify the additional detail the architecture should provide)

(b) If you indicated a need for extension, could you name here any other architecture and model which does cover the missing detail (give specifics). 


\section{Evaluation questionnaire for PERA}

\subsubsection{Redundancy}

Does this architecture require that existing standards must be rewritten (e.g. expressed in a new form without changing the content) in order to fit this architecture?

No

\subsubsection{System extensibility}

How do you ensure that systems created according to this architecture are open ended?

No answer provided.

If you judged that the architecture allows modular evolution, is this judgement based on

[ ] theoretical considerations

[ ] feasibility study or pilot project

[x] repeated industry experience [of the authors (Bernus)]

\subsubsection{Resilience}

Does the architecture provide any principles or guidance that will help the user to limit the effect of imposed external changes on the operation of the system?

The master plan, which describes the integrated architecture, provides a means for analyzing and locating the effects of change. Also resilience of individual systems in the face of technological changes is a feature of these systems which can be designed.

The division in the architecture, of control and material flow is one of the principles that separate the actual technology from the rest of the system. Thus as far as functional requirements are met technology changes have a localized effect. The same is true of the decision of how to mix human and automated functions.

\subsubsection{Skills required to implement}

Does the architecture adequately treat the skills required by the user to allow for the design and building of a specific system described by it? (give rating):

$[\mathrm{x}] \quad$ very good ${ }^{\mathrm{a}}$ 
a.The architecture is very good from this respect if the skills required are available or there are tried and natural, pragmatic ways for practitioners to extend their skills in the new direction.

The presentation of the architecture is apparently very well matching the view of industrial systems as perceived by engineers and managers. This has been verified in the process industry.

\subsubsection{Dependence on new technologies}

Does the implementation of this architecture require a given type of new technology for any application within the scope? (A technology is new in this respect if it has not yet been proven under industrial circumstances)?

[x] no new technology required

13.1.13 What is your opinion about the future prospects for this architecture?

\begin{tabular}{|c|c|c|c|}
\hline[] & {[]} & {[]} & {[]} \\
yes, widespread & yes, limited area & no & undecided \\
\hline
\end{tabular}

Example

[ ] [ ] [ ] [x] will have theoretical impact

[x] [ ] [ ] [ ] will gain industry acceptance in the present form

[x] [ ] [ ] [ ] will gain industry acceptance in developed (or modified) form

As evidenced by the Purdue CIM consortium

\subsubsection{What were the reasons for the development of this architec- ture?}

\begin{tabular}{|c|c|c|c|}
\hline $\begin{array}{c}\text { main } \\
\text { reason } \\
{[]}\end{array}$ & cofactor & $\begin{array}{c}\text { not a known } \\
\text { reason } \\
{[}\end{array}$ & $\begin{array}{c}\text { no information } \\
{[]}\end{array}$ \\
\hline
\end{tabular}

Example

[ ] [ ] [x] [ ] utilization in a given segment of industry

[ ] [ ] [x] [ ] development of a national standard

[ ] [ ] [x] [ ] development of an international standard

[ ] [ ] [x] [ ] utilization by a given firm

[x] [ ] [ ] [ ] utilization by a group of firms

$[\mathrm{x}][$ ] [ ] [ ] utilization for teaching purposes

[x] [ ] [ ] [ ] utilization for research purposes (Other, please specify) 
13.1.15 What is the driving force behind this architecture?

\begin{tabular}{|c|c|c|c|}
\hline $\begin{array}{c}{[]} \\
\text { main reason }\end{array}$ & $\begin{array}{c}{[]} \\
\text { cofactor }\end{array}$ & $\begin{array}{c}{[] \text { not a known }} \\
\text { reason }\end{array}$ & $\begin{array}{c}{[] \text { no }} \\
\text { information }\end{array}$ \\
\hline
\end{tabular}

Example

[x] [ ] [ ] [ ] technology pull (there was a perceived need in industry for which the generic architecture intends to be the answer)

[ ] [x] [ ] [ ] technology push (results in the area of architectures methodologies, information technology, communications manufacturing technology created opportunity or incentive for for industry to develop this generic CIM architecture)

Please expand your views on the above quesion if possible.

The success of the Purdue CIM Model for industrial control in the area of continuous industries has created the initiative to extend this concept to

- any type of industry

- all activities of the enterprise, not only process control

This cofactor made it possible to fill in the genuine need for an enterprise integration architecture and accompanying methodology.

\subsubsection{Adequacy}

Please rate the adequacy of the architecture with respect to the help which it provides for attaining the essential or important goals which you identified in Question 5.

There is not sufficient information in this respect (yet)

What is the main strength of this architecture?

Its graphical and easy to grasp presentation

The philosophy of how it divides concerns is meeting the way of thinking of industry practitioners

To your knowledge which essential or important goals (see Question 5) are specifically not adequately addressed by this architecture? Unknown 


\subsection{MODELLING}

\subsubsection{What kinds of models describe this architecture?}

Please characterize the models which this architecture requires to be produced? (The table for your answers has been broken into four parts because it had too many columns - see following pages).

Characterize the corresponding modelling languages used to express the models. NB. For the purposes of collecting information we have ordered these tables by the models and not by the modelling languages. Note, that because the same modelling language is often used for more than one model, it is enough to characterize the language only once. However, it is expected that the questions about the language's adequacy for each separate type of model will be answered separately.

The descriptions capturing requirements, designs, etc, are produced in many, very different, forms (formal mathematical models, graphs, natural language, tables) We use the word 'model' to refer to all of these forms.

Overall plans are incomplete at this point.

There is no commitment in the Purdue Architecture as to how (or whether) to develop formal models; at the moment it is up to the team creating the master plan what way of description suits best the given individual system's architecture.

Overall note: it appears that the Purdue architecture develops to great detail the architecture proper, while other approaches, like CIMOSA and GRAI, provide modelling framework and modelling methods to fill in the elements of the Purdue Architecture.

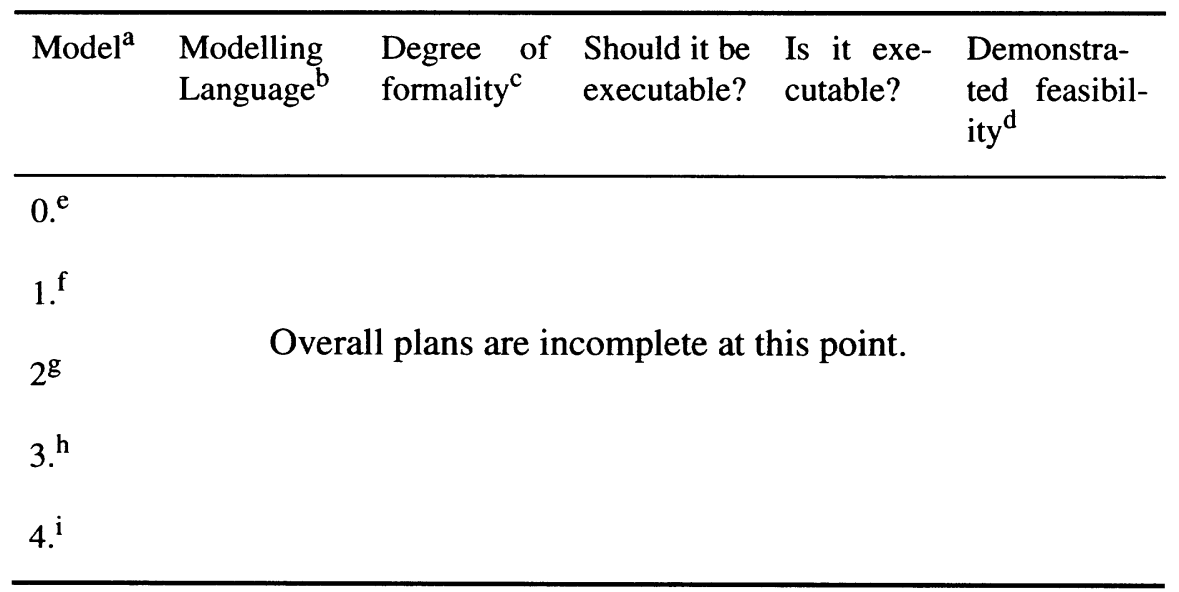


5.

$6 .^{k}$

7.1

Overall plans are incomplete at this point.

$8^{\mathrm{m}}$

$9 .^{\mathrm{n}}$

$100^{\circ}$

$11 .^{\mathrm{p}}$

a. Please add rows as necessary. E.g., 'functional requirements model,' 'organizational design model', etc. Note that if models are substantially different on various levels of genericity then you are asked to enter these as separate models.

b. Here add rows as necessary. E.g., 'functional requirements model,' 'organizational design model', etc. Note that if models are substantially different on various levels of genericity then you are asked to enter these as separate models.

c. Please rate: $\mathrm{I}=$ Informal, $\mathrm{S}=$ Structured but the expressive power of the formal part is not adequate (missing information being added in natural language), $\mathrm{F}=$ Formal mathematical model, with formal semantics.

d. This is the feasibility of producing an adequate model using this language, $\mathrm{P}=$ Practically demonstrated, $\mathrm{T}=$ Demonstrated in theory, or only $\mathrm{C}=$ Conjectured Please add further comments in footnotes and on separate pages if necessary.

e. Requirements for control

f. Management vision

g. Requirements for customer services (CS)

h. Task description (control)

i. Task description

j. Task and functional module description (control)

$\mathrm{k}$. Task and functinal module description (CS)

1. Information flow between tasks (control)

$\mathrm{m}$. Task interconnection (material and information) customer service

n. Information system architecture

o. Human and organizational architecture

p. Customer response architecture

Note: $(e)-(m)$ belong to the definition of the system architecture while $(n)-(p)$ are repeated for each of specification, detailed design, manifestation and operations. Levels of description of the systems architecture for items $((e)-(m)$ include management information, production scheduling anf planning, intraarea coordination, supervisory control, direct digital control, dedicated controllers and process. 


\begin{tabular}{lll}
\hline Model & $\begin{array}{l}\text { Adequacy of } \\
\text { modelling language }\end{array}$ & $\begin{array}{l}\text { Is there any related standard mod- } \\
\text { elling language? }\end{array}$ \\
\hline $0-11^{\mathrm{a}}$ & No sufficient information yet \\
\hline
\end{tabular}

a. see models $e-p$

\begin{tabular}{lllll}
\hline Model & $\begin{array}{l}\text { Verifiabilityof } \\
\text { model }\end{array}$ & $\begin{array}{l}\text { Could any } \\
\text { alternative lan- } \\
\text { guage be used? }\end{array}$ & $\begin{array}{l}\text { Can complete- } \\
\text { ness be } \\
\text { achieved? }\end{array}$ & $\begin{array}{l}\text { Supported by } \\
\text { CASE tool? }\end{array}$ \\
\hline
\end{tabular}

$0-11^{\mathrm{a}}$

No sufficient information yet

a. see models $e-p$

Model Adequacy of language for people Adequacy of language for those who should use/interpret the who should produce the model model

$0-11^{\mathrm{a}}$

No sufficient information yet

a. see models $e-p$

13.2.2 How well does the architecture describe the operational characteristics of an enterprise in contrast with describing only its basic design feature?

[x] operational characteristics can be explicitly specified

[ ] operational characteristics can be derived from the design

features (e.g. through simulation model)

The links are explicitly described in the Master Plan, however, automatic derivation (especially because of no committment to use formal models) is not possible.

\subsubsection{Formalism}

Do you think formal methods (with rigorously defined syntax and semantics) are needed to describe and interpret the architecture under discussion and the representation of particular systems by it? 
[x] not necessary in general

Please comment on what areas you have applied or intend to apply formal methods?...

This view may change later, however at present there is no full evidence apart from specific subsystems (E.g., critical software modules need to be formally specified and verified).

Could there be a formal canonical view developed together with a modelling language which would subsume all of the ones used? If yes, please specify what should be the characteristics of such a language:

Unknown at present, in the lack of sufficient experimental evidence.

Do you think that the scope of the formal methods is broad enough to capture what you want to describe?

No answer provided

Can people who need to deal with these models easily relate to these formalisms?

No answer provided

\subsubsection{Verification support}

How extensively are Computer Aided Engineering (CAE) tools available to verify the prescribed models? No answer provided

Do you think it is necessary to have CAE tools to support the methodolog

No answer provided

Are there any limitations to achieving the above? No answer provided

How well can the architecture be used to verify the completeness and adequacy of the overall design for an enterprise or any of its components? (Please comment on merits and problems.)

The verification of the architectures based on the generic Purdue Architecture is a human design process. The Implementation Procedures Manual, which is the extensive cookbook style description of how to write a master plan can be followed to ensure complete coverage of the subject.

\subsubsection{Economic questions}

How well does the associated methodology handle economic questions related to the enterprise described using its methods? (Give comments)

$[\mathrm{x}] \quad$ well covered 


\subsection{METHODOLOGY}

\subsubsection{Does the architecture have a methodology connected to it?}

[x] yes (please give the name of the methodology) Purdue Methodology If possible, can you specify what are the components of the methodology?

The 'Purdue Architecture' is the base framework for the 'Implementation Procedures Manual' (IPM). The IPM corresponds in structure to the Master Plan describing in detail how a Master Plan can be created. How complete is the methodology?

[x] this is a complete methodology, covering all aspects of enterprise engineering activity

[ ] the methodology is a collection of methods/logical techniques (but only separate methodologies are available for the individual modelling tasks)

[ ] the methodology is planned to be a complete one

Does the methodology address the human factor in the enterprise?

[x] treats the necessary human organization

$[\mathrm{x}] \quad$ skill levels for operating personnel

[x] training requirements

[x] treats teams

[x] treats individual workers

\subsubsection{Validation status of the methodology}

Was the methodology validated

[x] in implemented industry projects/systems

[x] other: Case studies. Accepted by potential users

Could you give references? No answer provided

\subsubsection{Maturity of the methodology}

The methodology has been

[x] successfully taught by others than its developers

[x] successfully applied by other than its developers

[x] repeatedly applied by its developers

[x] shown to work by its developers 


\subsubsection{Scope of the methodology}

\begin{tabular}{|l|l|l|l|l|}
\hline $\begin{array}{l}\text { [] exten- } \\
\text { sive cover- } \\
\text { age }\end{array}$ & $\begin{array}{l}{[] \text { some }} \\
\text { coverage }\end{array}$ & $\begin{array}{l}{[] \text { no }} \\
\text { coverage }\end{array}$ & $\begin{array}{l}{[] \text { no }} \\
\text { informa- } \\
\text { tion }\end{array}$ & $\begin{array}{l}\text { [] not } \\
\text { applicable }\end{array}$ \\
\hline
\end{tabular}

Check appropriate fields of the table.

\begin{tabular}{ll|l|l}
\hline $\begin{array}{l}\text { Activities and } \\
\text { related } \\
\text { methods to }\end{array}$ & $\begin{array}{l}\text {...common to all } \\
\text { systems in the } \\
\text { scope }\end{array}$ & $\begin{array}{l}\text {...common to a } \\
\text { family of systems } \\
\text { in the scope } \\
\text { (which one?) }\end{array}$ & \multicolumn{1}{l}{$\begin{array}{l}\text {..of individual } \\
\text { systems }\end{array}$} \\
\hline $\begin{array}{l}\text { produce } \\
\text { requirements... }\end{array}$ & [ ] [x] [ ] [ ] [ ] & [ ] [ ] [ ] [ ] [ ] & [ ] [x] [ ] [ ] [ ] \\
$\begin{array}{l}\text { produce the } \\
\text { design } \\
\text { specifications... }\end{array}$ & [ ] [x] [ ] [ ] [ ] & [ ] [ ] [ ] [ ] [ ] & [ ] [x] [ ] [ ] [ ] \\
$\begin{array}{l}\text { produce the } \\
\text { detailed design... }\end{array}$ & [ ] [x] [ ] [ ] [ ] & [ ] [ ] [ ] [ ] [ ] & [ ] [x] [ ] [ ] [ ] \\
$\begin{array}{l}\text { produce the } \\
\text { system... }\end{array}$ & [ ] [x] [ ] [ ] [ ] & [ ] [ ] [ ] [ ] [ ] & [ ] [x] [ ] [ ] [ ] \\
$\begin{array}{l}\text { produce the } \\
\text { operational and } \\
\text { maintenance } \\
\text { methods... }\end{array}$ & [ ] [x] [ ] [ ] [ ] & [ ] [ ] [ ] [ ] [ ] & [ ] [x] [ ] [ ] [ ] \\
\hline
\end{tabular}

a. The methodology does not tackle 'partial models' (a term borrowed from CIMOSA). However the architecture may accommodate the concept of partial model/description. Partial and particular models flow from the generic Purdue Models.

Example: check 'extensive coverage' box in upper right hand corner if the methodology extensively tackles 'activities and related methods to produce the requirements of individual systems,' to be read from the table as:

Activities and related methods to produce the requirements ... ...of individual systems. 
13.3.5 Presentation of the methodology

\begin{tabular}{|c|c|c|c|c|c|c|}
\hline $\begin{array}{c}{[]} \\
\text { extensive } \\
\text { planned }\end{array}$ & $\begin{array}{c}{[]} \\
\text { some } \\
\text { planned }\end{array}$ & $\begin{array}{c}{[]} \\
\text { extensive } \\
\text { now }\end{array}$ & $\begin{array}{c}{[]} \\
\text { some now }\end{array}$ & $\begin{array}{c}{[]} \\
\text { none }\end{array}$ & $\begin{array}{c}{[]} \\
\text { no info. }\end{array}$ & $\begin{array}{c}{[]} \\
\text { not } \\
\text { applicable }\end{array}$ \\
\hline
\end{tabular}

[ ] [ ] [x] [ ] [ ] [ ] [ ] handbook or collection of handbooks

[ ] [ ] [x][ ][ ][ ][ ] teaching material

[][]$[\mathrm{x}][\mathrm{]}][\mathrm{]}] \mathrm{]}] \mathrm{]}$ organizational procedures

[ ] [ ] [ ] [ ] [x] [ ] [ ] CASE tool support for individuals

[ ] [ ] [ ] [x][ ][ ] [ ] project database

[ ] [ ] [ ] [ ] [x] [ ] [ ] CASE tool support for project team

\subsubsection{Genericity}

We want to know how big the gap is between the methodology as presented (see Question 26) and the way it is applied in particular projects.

[x] the methodology describes general procedures only

[ ] the methodology is supported by a collection of application examples / cookbook

\subsubsection{Quality of the methodology}

Please rate the methodology from the following aspects:

\begin{tabular}{|c|c|c|c|c|c|}
\hline $\begin{array}{c}\text { poor } \\
{[]}\end{array}$ & average & good & excellent & no info. & N/A \\
{[]} & {[]} & {[]} & {[]} & {[]} \\
\hline
\end{tabular}

Since this methodology is new, there is no implementation experience as (as of 1992) 